\title{
Phthalate exposure and childhood obesity
}

\author{
Shin Hye Kim, MD, \\ Mi Jung Park, MD, PhD \\ Department of Pediatrics, Inje \\ University Sanggye Paik Hospital, \\ Inje University College of Medicine, \\ Seoul, Korea
}

Phthalates are commonly used as plasticizers and vehicles for cosmetic ingredients. Phthalate metabolites have documented biochemical activity including activating peroxisome proliferator-activated receptor and antiandrogenic effects, which may contribute to the development of obesity. In vitro and in vivo studies suggest that phthalates have significant effects on the development of obesity, especially after prenatal exposure at low doses. Although few studies have examined the effects of phthalate on obesity development in humans, some work has shown that phthalates affect humans and animals similarly. In this paper, we review the possible mechanisms of phthalate-induced obesity, and discuss evidence supporting the role of phthalates in the development of obesity in humans.

\section{Keywords: Diethylhexyl phthalate, Child, Endocrine disruptors, Obesity}

\section{Introduction}

Between the late 1970s and the early 2000s, the prevalence of obesity among Korean children and adolescents rapidly increased nearly $10 \mathrm{folds}^{1)}$. Although the rate of obesity has been leveled off, it remains prevalent particularly in boys ${ }^{2}$. In general, the increased prevalence of obesity is attributed to overeating, a sedentary life style, and genetic susceptibility. Although high-calorie fast foods and soft drinks are easily available, and people spend more time participating in sedentary activities, such as watching television or using a computer, these factors are insufficient to explain the huge increase in obesity during the 20th century ${ }^{3)}$. In 2002, Baillei-Hamilton ${ }^{4)}$ proposed that the global obesity epidemic was caused by exposure to endocrine disrupting chemicals (EDCs), and demonstrated that increased production of industrial chemicals coincided with increased obesity in the Unites States. A subset of EDCs that promote weight gain and obesity are referred to as "obesogens" ${ }^{\text {"5) }}$. Obesogens may cause obesity in several ways including disruption of critical lipid metabolism pathways to promote adipogenesis and fat storage, the alteration of the metabolic set point to induce positive energy balance, or increasing appetite ${ }^{5}$. Indeed, there is evidence showing a positive associations between obesogen levels, including phthalates, and body weight or body mass index (BMI) in children and adults.

Phthalates are diesters of 1,2-benzenedicaraboxylic acid (phthalic acid) and are used to increase the softness and flexibility of plastic products and as vehicles for fragrance in cosmetics. They are widely found in a variety of household products or personal care products, including building materials, shower curtains, children's toys, food packaging, and medical devices. Human exposure to phthalates can occur through ingestion of contaminated food and water, dermal contact, inhalation of polluted air, and parental exposure from medical devices). Several in vivo and in vitro studies suggest that phthalates may promote obesity through antiandrogenic effects, antithyroid hormone activities, and/or activation of peroxisome proliferator-activated receptors (PPARs). Recently, human studies have been performed to study the association between phthalate exposure and obesity. Children are known to be more vulnerable to environmental exposure to phthalates, as compared to adults, because of their hand-to-mouth activity, larger surface area to weight ratio, and enhanced metabolic rate. As a 
result, there have been concerns that phthalates may promote childhood obesity in recent years.

In this paper, we review the possible mechanisms by which phthalate might influence the development of obesity, and discuss evidence from human studies suggesting an association between phthalate exposure and obesity-related biomarkers.

\section{Diester phthalates and their potential sources of exposure}

Phthalates have been used as plasticizers since the 1930s, and are currently used as additives in various consumer products (Table 1). The global consumption of phthalates is estimated to be several million tons per year ${ }^{7)}$. High molecular weight (HMW) phthalates, such as di-2-ethylhexyl phthalate (DEHP) and diisononyl phthalate (DiNP) are used primarily in the manufacture of polyvinyl chloride (PVC) plastics for food packaging, building materials, and medical devices. Low molecular weight (LMW) phthalates, such as diethyl phthalate (DEP) and butylbenzyl phthalate (BBzP) are typically used in the manufacture of personal care products (e.g., perfumes, lotions, cosmetics, shampoo), paints, and adhesives. Phthalates are continuously emitted from PVC and plastic materials, resulting in contamination of indoor air, house dust, or food ${ }^{6,7)}$. As a result, the primary methods of HMW phthalate exposure are ingestion of contaminated food or dust, or parental exposure. In contrast, the primary methods of LMW phthalate exposure are inhalation or dermal contact.

\section{Metabolism of phthalates}

Phthalates are rapidly metabolized and excreted in urine and feces after exposure. Fig. 1 demonstrates the metabolism of phthalates. In phase I hydrolysis, diester phthalates are hydrolyzed by esterases and lipases in the intestine and parenchyma to their respective monoester phthalates ${ }^{8}$. LMW phthalates are primarily excreted in urine and feces as a monoester, without further metabolism. In contrast, HMW phthalates are further metabolized from monoesters through hydroxylation or oxidation, to produce a number of oxidative metabolites. The oxidative metabolites of phthalates are excreted in urine within 24 hours of exposure. Alternatively, oxidative metabolites can undergo phase II conjugation to form hydrophilic glucuronide conjugates, which are excreted in urine rapidly ${ }^{8}$. Hydrolytic monoester phthalates can be measured in blood, urine, breast milk, and feces for use as the biomarkers of exposure to the corresponding phthalate diesters. Urinary phthalate metabolites are the most useful biomarkers, as they are relatively easy to collect and their levels in a single sample reflect the exposure to phthalates over several weeks or months ${ }^{9,10)}$. The major biomarker of phthalates with short alkyl chains, such as di-n-butyl phthalate (DBP) and BBzP, are their monoesters

Table 1. Diester phthalates and their potential sources of exposure

\begin{tabular}{|c|c|c|}
\hline Phthalate (Abbreviation) & Sources of exposure & Metabolites \\
\hline \multicolumn{3}{|l|}{ Low molecular weight } \\
\hline Dimethyl phthalate (DMP) & $\begin{array}{l}\text { Personal care products } \\
\text { (deodorant, fragrance atershaves, shampoos, hair styling) }\end{array}$ & Monomethyl phthalate (MMP) \\
\hline Dietyl phthalate (DEP) & $\begin{array}{l}\text { Personal care products (deodorant, fragrance aftershaves, } \\
\text { shampoos, hair styling, skin care, nail care, makeup, } \\
\text { baby preperations) }\end{array}$ & Monoethyl phthalate (MEP) \\
\hline Di-n-butyl phthalate (DBP) & $\begin{array}{l}\text { Paints, adhesives, Personal care products } \\
\text { (perfumes, aftershaves, nail care, makeup) }\end{array}$ & Mono-n-butyl phthalate (MBP) \\
\hline Di-iso-butyl phthalate (DiBP) & Paints, adhesives & Mono-iso-butyl phthalate (MiBP) \\
\hline \multicolumn{3}{|l|}{ High molecular weight } \\
\hline Butylbenzyl phthalate (BBzP) & $\begin{array}{l}\text { Paint, adhesives, car care products, toys, food packaging, } \\
\text { synthetic leather, deodorants, }\end{array}$ & Monobenzyl phthalate (MBzP) \\
\hline Di (2-ethylhexyl) phthalate (DEHP) & $\begin{array}{l}\text { Household products (toys, floor tiles, wall coverings, } \\
\text { furniture, paints, adhesives, gloves), dust, food packaging, } \\
\text { medical devices }\end{array}$ & $\begin{array}{l}\text { Mono(2-ethylhexyl) phthalate (MEHP) } \\
\text { Mono(2-ethyl-5-hydroxylhexyl) phthalate (MEHHP) } \\
\text { Mono(2-ethyl-5-oxohexyl) phthalate (MEOHP) } \\
\text { Mono(2-ethyl-5-carboxypentyl) phthalate (MECPP) } \\
\text { Mono(2-carboxy-hexyl) phthalate (MCHP) }\end{array}$ \\
\hline Di-iso-nonyl phthalate (DiNP) & $\begin{array}{l}\text { Household products (toys, floor tiles, wall coverings, } \\
\text { furniture, paints, adhesives, gloves), clothes and footwear, } \\
\text { car interiors, food packaging, medical devices }\end{array}$ & $\begin{array}{l}\text { Mono-iso-nonyl phthalates (MiNP) } \\
\text { Mono(hydroxy-iso-nonyl) phthalate (MHiNP) } \\
\text { Mono(oxo-iso-nonyl) phthalate (MOiNP) } \\
\text { Mono(carboxy-iso-octyl) phthalate (MCiOP) }\end{array}$ \\
\hline Di-n-octyl phthalate (DnOP) & $\begin{array}{l}\text { Household products (floorings, carpet tiles, vinyl gloves, } \\
\text { garden hoses, wire and cable insulation, adhesives), } \\
\text { food applications (package sealants, bottle cap liners) }\end{array}$ & $\begin{array}{l}\text { Mono-(3-carboxypropyl) phthalate (MCPP) } \\
\text { Mono-n-octyl phthalate (MOP) }\end{array}$ \\
\hline Di-isodecyl phthalate (DiDP) & $\begin{array}{l}\text { Household products (toys, coated fabrics, vinyl flooring, } \\
\text { wall coverings, lamination film, wire and cable insulation, } \\
\text { foot wear, paints, adhesives), school supplies } \\
\text { (scented erasers and pencil case) }\end{array}$ & $\begin{array}{l}\text { Mono-isodecyl phthalate (MiDP) } \\
\text { Mono-(carboxynonyl) phthalate (MCNP) }\end{array}$ \\
\hline
\end{tabular}




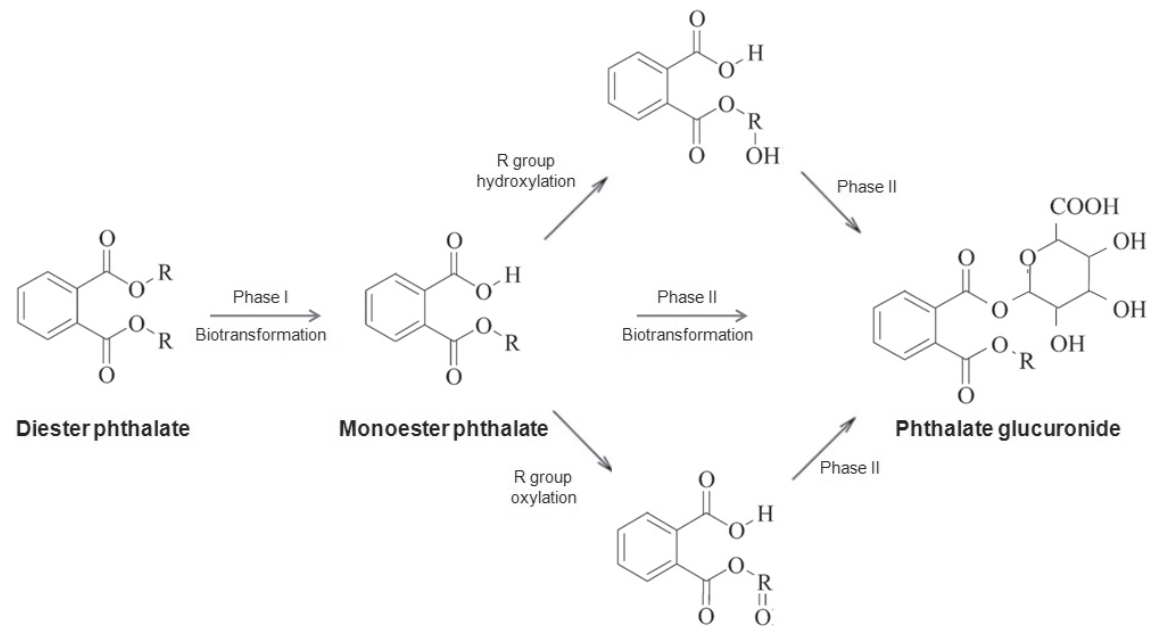

Fig. 1. Metabolic pathways of phthalates.

in urine ${ }^{7}$. However, in the case of DEHP and DiNP, which are further metabolized from their primary monoesters and yield numerous oxidative metabolites, exposure must be estimated by taking the sum of primary and secondary metabolites in urine ${ }^{11)}$. When daily phthalate intake was estimated in children using urinary phthalate biomarkers, DEHP was the most abundant phthalate, followed by DBP, di-iso-butyl phthalate, $\mathrm{DEP}$ and $\mathrm{BBz}^{12}$.

\section{Plausible mechanisms of phthalates effects on obesity}

PPARs serve as metabolic sensors for various lipophilic hormones, fatty acids, and fatty acid metabolites, thereby controlling adipocyte proliferation and differentiation ${ }^{5}$. PPARa is highly expressed in liver, heart, skeletal muscle, gonads, and brown adipose tissue, where mediates peroxisome proliferation and stimulate fatty acid $\beta$-oxidation ${ }^{13-15)}$. PPAR $\alpha$ activators exert a variety of metabolic actions, depending on to the species, gender, dose, and timing of exposure. High doses DEHP protected adult mice from diet-induced obesity by promoting fatty acid oxidation and catabolic metabolism by activating PPARa ${ }^{16}$. In contrast, in mice expressing human PPARa, exposure to DEHP promoted fat accumulation and exacerbated obesity. Further, fetal exposure to low doses of mono(2-ethylhexyl) phthalate (MEHP) significantly increased the body weight of male offspring at postnatal day 60 , whereas these effects were not evident in female offspring ${ }^{17}$. In rodents, phthalate monoesters, including MEHP and mono-nbutyl phthalate, are responsible for deformation of the male reproductive tract and dysfunction of both Leydig and Sertoli cells, resulting in decreased testosterone/androgen production and impaired spermatogenesis ${ }^{13,18}$. Importantly, phthalates do not interact with androgen receptors directly; rather their anti-androgenic effects are mediated through PPAR ${ }^{13,18)}$. The antiandrogenic effects of phthalates have also been demonstrated in infants and adults ${ }^{19,20)}$. As decreased androgen activity induces obesity, the anti-androgen effect through PPAR $a$ may be a possible mechanism of phthalate-induced obesity.

PPAR $\gamma$ is mainly expressed in adipose tissue, It plays a number of key roles including regulating the differentiation of adiopocytes and fat accumulation/storage in the adipose tissue. Additionally, PPAR $\gamma$ improves insulin sensitivity ${ }^{211}$. PPAR $\gamma$ agonists, such as thiazolidinediones, are potent insulin sensitizing agents used to control hyperglycemia in type 2 diabetes. However, their side effects include weight gain, which limits their usage in obese patients. Some phthalate monoesters, such as MEHP, mono-iso-nonyl phthalates, and monoisodecyl phthalate act as PPAR $\gamma$ agonists, thereby promoting differentiation and lipid accumulation in 3T3-L1 cells, similar to thiazolidinediones ${ }^{22,23)}$. Therefore, it is likely that phthalates exert an adipogenic effect though the activation of PPAR $\gamma$. However, few in vivo animal studies have been performed to assess the effects of phthalate on PPAR $\gamma$ and adipogenesis ${ }^{17}$.

Another possible mechanism by which phthalates might promote obesity is through the disruption of thyroid function, which plays a key role in the regulation of energy balance and metabolism. There is some evidence that thyroid function plays a role in the regulation of BMI, as small changes in thyroidstimulating hormone (TSH) or thyroxine levels within the normal range can cause measurable differences in resting energy expenditure in chronic hypothyroidism patients, and slight elevation of serum TSH levels are associated with both weight gain over 5 years and obesity in a population study ${ }^{24,25)}$. In rodent studies, exposure to DEHP lowered plasma thyroxine and decreased iodide uptake of thyroid follicular cells ${ }^{26,27)}$. Recent human studies have also demonstrated possible effects of phthalate exposure on thyroid function in children and adults $^{28-31)}$.

Finally, the "thrifty phenotype" resulting from exposure to undernourished fetal environment and EDCs could be one of plausible mechanisms by which phthalates promote obesity ${ }^{32)}$. 
Epigenetic changes, induced by a suboptimal fetal environment, may result in increased uptake and conservation of nutrients, and predispose individuals to obesity and other metabolic disorders $^{32)}$. Epidemiological studies provide evidence that maternal malnutrition during pregnancy and subsequent low birth weight is associated with obesity later in life ${ }^{33-35)}$. In rodent studies, maternal exposure to DBP or DEHP during the gestational period have been reported to decrease birth weight in offsprings ${ }^{36,37)}$. Studies regarding of the effect of phthalate exposure on preterm delivery and/or fetal growth in humans are limited and conflicting. Some studies suggested that there is a positive association between fetal phthalate exposure and premature delivery or lower birth weight ${ }^{38-40)}$, but other studies failed to show a significant relationship ${ }^{41,42)}$. Prospective investigations are needed to reveal the validity of the hypothesis that phthalate exposure results in low birth weight and subsequent obesity.

\section{Phthalate exposure and obesity development in human}

Table 2 presents the results of human studies investigating the effects of phthalate exposure on obesity. Most epidemiologic studies examining the association between phthalate exposure and obesity have been based on the data from the National Health and Nutrition Examination Survey (NHANES) ${ }^{43-46)}$. Regarding adulthood obesity, Stahlhut et al. ${ }^{43)}$ demonstrated a positive association between urinary monoethyl phthalate (MEP), monobenzyl phthalate, mono(2-ethyl-5-hydroxylhexyl) phthalate, and mono(2-ethyl-5-oxohexyl) phthalate and waist circumference (WC) in male adults, using data from NHANES 1999-2002 ${ }^{43)}$. Using the same data, Hatch et al. ${ }^{44)}$ showed a positive association between urinary MEP and both BMI and WC in female adults. Recently, a study from NHANES 2007-2010 found that HMW phthalates were associated with an increased risk of obesity in male adults, while DEHP phthalates were associated with increased obesity in females ${ }^{46)}$. A prospective study from Sweden investigated serum phthalate metabolites in elderly subjects (70 years), and measured their body composition by dual-energy X-ray absorptiometry (DXA) two years later. In this study, serum mono-isobutyl phthalate levels were significantly correlated with increased BMI, WC, total fat mass and trunk fat mass by DXA in females, but not in males $^{47)}$.

Table 2. Human studies on phthalate exposure and obesity development

\begin{tabular}{|c|c|c|c|}
\hline Study population & Exposure assessment & Findings & Reference \\
\hline $\begin{array}{l}\text { US, male participants from } \\
\text { NHANES 1999-2002 } \\
\text { aged }>18 \text { yr }(n=1,443)\end{array}$ & $\begin{array}{l}\text { Cross-sectional study } \\
\text { Urine - } 6 \text { phthalates (MBP, MEP, MEHP, MBzP, } \\
\text { MEHHP, MEOHP) }\end{array}$ & $\begin{array}{l}\text { Positive association between WC and MEP, MBzP, } \\
\text { MEHHP, MEOHP }\end{array}$ & Stahlhut et al. ${ }^{43)}$ \\
\hline $\begin{array}{l}\text { US, participants from } \\
\text { NHANES 1999-2002 } \\
\text { aged 6-80 yr }(n=6,369)\end{array}$ & $\begin{array}{l}\text { Cross-sectional study } \\
\text { Urine - } 6 \text { phthalates (MBP, MEP, MEHP, MBzP, } \\
\text { MEHHP, MEOHP) }\end{array}$ & $\begin{array}{l}\text { Positive association between BMI/WC and MEP, } \\
\text { MBzP, MBP, MEHHP, MEOHP in males aged } \\
20-59 \mathrm{yr} \\
\text { Positive association between BMI/WC and MEP in } \\
\text { females aged 12-59 yr } \\
\text { Negative association between BMI and MEHP in } \\
\text { females aged 12-59 yr }\end{array}$ & Hatch et al. ${ }^{44)}$ \\
\hline $\begin{array}{l}\text { US, participants from } \\
\text { NHANES 2007-2010 } \\
\text { aged }>6 \mathrm{yr}\end{array}$ & $\begin{array}{l}\text { Cross-sectional study } \\
\text { Urine - } 10 \text { phthalates } \\
\text { LMW phthalates (MBP, MEP, MiBP), } \\
\text { HMW phthalates (MECPP, MEHHP, MEOHP, } \\
\text { MEHP, MBzP, MCNP, MCOP) }\end{array}$ & $\begin{array}{l}\text { Positive association between obesity risk and } \\
\text { LMW metabolites in males aged } 6-19 \mathrm{yr} \\
\text { Positive associations between obesity risk and } \\
\text { HMW metabolites in males aged }>20 \mathrm{yr} \\
\text { Positive associations between obesity risk and } \\
\text { DEHP metabolites in females aged }>20 \mathrm{yr}\end{array}$ & Buser et al. ${ }^{46)}$ \\
\hline $\begin{array}{l}\text { Sweden, elderly aged } 70 \mathrm{yr} \\
(\mathrm{n}=1,016)\end{array}$ & $\begin{array}{l}\text { Prospective study } \\
\text { Blood- } 4 \text { phthalates } \\
\text { MEP, MEHP, MiBP, MMP }\end{array}$ & $\begin{array}{l}\text { Positive association between MEP and WC/fat } \\
\text { mass obtained } 2 \text { yr later among females }\end{array}$ & Lind et al. ${ }^{47)}$ \\
\hline $\begin{array}{l}\text { US, participants from } \\
\text { NHANES 2003-2008 } \\
\text { aged 6-19 yr }(n=2,884)\end{array}$ & $\begin{array}{l}\text { Cross-sectional study } \\
\text { Urine }-9 \text { phthalates } \\
\text { LMW phthalates (MBP, MEP, MiBP), } \\
\text { HMW phthalates (MECPP, MCPP, MEHHP, } \\
\text { MEOHP, MEHP, MBzP) }\end{array}$ & $\begin{array}{l}\text { Positive association between obesity risk and } \\
\text { sum of molar concentrations LMW phthalates } \\
\text { among non-Hispanic blacks }\end{array}$ & Trasande et al. ${ }^{45)}$ \\
\hline $\begin{array}{l}\text { New York, children } \\
\text { aged 6-8 yr } \\
\text { Hispanic and Black }\end{array}$ & $\begin{array}{l}\text { Prospective study } \\
\text { Urine - } 9 \text { phthalates } \\
\text { LMW phthalates (MBP, MEP, MiBP), } \\
\text { HMW phthalates (MECPP, MCPP, MEHHP, } \\
\text { MEOHP, MEHP, MBzP) }\end{array}$ & $\begin{array}{l}\text { Positive association between LMW phthalates } \\
\text { and BMI/WC obtained } 1 \text { yr later among } \\
\text { overweight children } \\
\text { No associations among normal weight subjects }\end{array}$ & Teitelbaum et al. ${ }^{48)}$ \\
\hline
\end{tabular}

NHANES, National Health and Nutrition Examination Survey; MBP, mono-n-butyl phthalate; MEP, monoethyl phthalate; MEHP, mono(2ethylhexyl) phthalate; MBzP, monobenzyl phthalate; MEHHP, mono(2-ethyl-5-hydroxylhexyl) phthalate; MEOHP, mono(2-ethyl-5-oxohexyl) phthalate; WC, waist circumference; BMI, body mass index; LMW, low molecular weight; MiBP, mono-iso-butyl phthalate; MECPP, mono(2ethyl-5-carboxypentyl) phthalate; MCNP, mono-(carboxynonyl) phthalate; MCOP, mono(carboxyoctyl) phthalate; DEHP, di(2-ethylhexyl) phthalate ; MMP, monomethyl phthalate; HMW, high molecular weight; MCPP, mono(3carboxypropyl) phthalate. 
Emerging evidence suggest childhood exposure to some phthalates also may increase the risk of obesity. In a study of Hatch et al. ${ }^{44)}$, BMI and WC increased with urinary MEP concentrations among female girls in the United States. Two recent studies using data from NHANES found that urinary levels of LMW phthalates were associated with higher odds for obesity in children and adolescents ${ }^{45,46)}$. A prospective cohort study also found that urinary LMW phthalate metabolite concentrations were positively associated with BMI in overweight children. However, no associations were reported among all the total subjects or normal weight subjects alone ${ }^{48)}$. The health effects of phthalate exposure appear to be complex, as they are dependent on several factors, such as the time of exposure, level of exposure, type of phthalates, and other environmental/genetic factors of the individuals.

\section{Conclusions}

Many in vitro studies indicate that phthalates are likely obesogens, promoting obesity via several mechanisms, including activation of PPARs, antithyroid effects, and epigenetic modulation. The fetal period appears to be a critical window for exposure, and differential effects are observed depending on the dose of phthalates received and gender. Recent human studies have examined the possible effects of phthalate exposure on the development of obesity, although most of them are cross-sectional and short-term prospective studies. Although the random concentrations of phthalate metabolites have good reproducibility, large-scaled longitudinal study including measures at different life ages is needed to establish the impact of phthalate exposure on the obesity epidemic.

\section{Conflict of interest}

No potential conflict of interest relevant to this article was reported.

\section{Acknowledgments}

This work was supported by grant 11162KFDA701 from the Korea Food \& Drug Administration in 2011.

\section{References}

1. Park YS, Lee DH, Choi JM, Kang YJ, Kim CH. Trend of obesity in school age children in Seoul over the past 23 years. Korean J Pediatr 2004;47:247-57.

2. Kim KE, Kim SH, Park S, Khang YH, Park MJ. Changes in prevalence of obesity and underweight among Korean children and adolescents: 1998-2008. Korean J Obes 2012;21:228-35.

3. Morris JN. Obesity in Britain: lifestyle data do not support sloth hypothesis. BMJ 1995;311:1568-9.
4. Baillie-Hamilton PF. Chemical toxins: a hypothesis to explain the global obesity epidemic. J Altern Complement Med 2002;8:185-92.

5. Hauser R, Calafat AM. Phthalates and human health. Occup Environ Med 2005;62:806-18.

6. Wormuth M, Scheringer M, Vollenweider M, Hungerbuhler K. What are the sources of exposure to eight frequently used phthalic acid esters in Europeans? Risk Anal 2006;26:80324.

7. Calafat AM, McKee RH. Integrating biomonitoring exposure data into the risk assessment process: phthalates [diethyl phthalate and di(2-ethylhexyl) phthalate] as a case study. Environ Health Perspect 2006;114:1783-9.

8. Hauser R, Meeker JD, Park S, Silva MJ, Calafat AM. Temporal variability of urinary phthalate metabolite levels in men of reproductive age. Environ Health Perspect 2004;112:1734-40.

9. Teitelbaum SL, Britton JA, Calafat AM, Ye X, Silva MJ, Reidy JA, et al. Temporal variability in urinary concentrations of phthalate metabolites, phytoestrogens and phenols among minority children in the United States. Environ Res 2008;106:257-69.

10. Wittassek M, Angerer J. Phthalates: metabolism and exposure. Int J Androl 2008;31:131-8.

11. Beko G, Weschler CJ, Langer S, Callesen M, Toftum J, Clausen G. Children's phthalate intakes and resultant cumulative exposures estimated from urine compared with estimates from dust ingestion, inhalation and dermal absorption in their homes and daycare centers. PLoS One 2013;8:e62442.

12. Grun F, Blumberg B. Endocrine disrupters as obesogens. Mol Cell Endocrinol 2009;304:19-29.

13. Corton JC, Lapinskas PJ. Peroxisome proliferator-activated receptors: mediators of phthalate ester-induced effects in the male reproductive tract? Toxicol Sci 2005;83:4-17.

14. Grygiel-Gorniak B. Peroxisome proliferator-activated receptors and their ligands: nutritional and clinical implications--a review. Nutr J 2014;13:17.

15. Larsen TM, Toubro S, Astrup A. PPARgamma agonists in the treatment of type II diabetes: is increased fatness commensurate with long-term efficacy? Int J Obes Relat Metab Disord 2003;27:147-61.

16. Feige JN, Gerber A, Casals-Casas C, Yang Q, Winkler C, Bedu E, et al. The pollutant diethylhexyl phthalate regulates hepatic energy metabolism via species-specific PPARalphadependent mechanisms. Environ Health Perspect 2010;118:234-41.

17. Hao C, Cheng X, Xia H, Ma X. The endocrine disruptor mono-(2-ethylhexyl) phthalate promotes adipocyte differentiation and induces obesity in mice. Biosci Rep 2012;32:619-29

18. Foster PM, Mylchreest E, Gaido KW, Sar M. Effects of phthalate esters on the developing reproductive tract of male rats. Hum Reprod Update 2001;7:231-5.

19. Main KM, Mortensen GK, Kaleva MM, Boisen KA, 
Damgaard IN, Chellakooty M, et al. Human breast milk contamination with phthalates and alterations of endogenous reproductive hormones in infants three months of age. Environ Health Perspect 2006;114:270-6.

20. Pan G, Hanaoka T, Yoshimura M, Zhang S, Wang P, Tsukino $\mathrm{H}$, et al. Decreased serum free testosterone in workers exposed to high levels of di-n-butyl phthalate (DBP) and di-2-ethylhexyl phthalate (DEHP): a cross-sectional study in China. Environ Health Perspect 2006;114:1643-8.

21. Lehrke M, Lazar MA. The many faces of PPARgamma. Cell 2005;123:993-9.

22. Hurst CH, Waxman DJ. Activation of PPARalpha and PPARgamma by environmental phthalate monoesters. Toxicol Sci 2003;74:297-308.

23. Bility MT, Thompson JT, McKee RH, David RM, Butala JH, Vanden Heuvel JP, et al. Activation of mouse and human peroxisome proliferator-activated receptors (PPARs) by phthalate monoesters. Toxicol Sci 2004;82:170-82.

24. al-Adsani H, Hoffer LJ, Silva JE. Resting energy expenditure is sensitive to small dose changes in patients on chronic thyroid hormone replacement. J Clin Endocrinol Metab 1997;82:1118-25.

25. Knudsen N, Laurberg P, Rasmussen LB, Bulow I, Perrild $\mathrm{H}$, Ovesen $\mathrm{L}$, et al. Small differences in thyroid function may be important for body mass index and the occurrence of obesity in the population. J Clin Endocrinol Metab 2005;90:4019-24.

26. Erkekoglu P, Giray BK, Kizilgun M, Hininger-Favier I, Rachidi W, Roussel AM, et al. Thyroidal effects of di-(2ethylhexyl) phthalate in rats of different selenium status. J Environ Pathol Toxicol Oncol 2012;31:143-53.

27. Wenzel A, Franz C, Breous E, Loos U. Modulation of iodide uptake by dialkyl phthalate plasticisers in FRTL-5 rat thyroid follicular cells. Mol Cell Endocrinol 2005;244:6371.

28. Meeker JD, Calafat AM, Hauser R. Di(2-ethylhexyl) phthalate metabolites may alter thyroid hormone levels in men. Environ Health Perspect 2007;115:1029-34.

29. Meeker JD, Ferguson KK. Relationship between urinary phthalate and bisphenol A concentrations and serum thyroid measures in U.S. adults and adolescents from the National Health and Nutrition Examination Survey (NHANES) 2007-2008. Environ Health Perspect 2011;119:1396-402.

30. Boas M, Frederiksen H, Feldt-Rasmussen U, Skakkebæk NE, Hegedus L, Hilsted L, et al. Childhood exposure to phthalates: associations with thyroid function, insulinlike growth factor I, and growth. Environ Health Perspect 2010;118:1458-64.

31. Wu MT, Wu CF, Chen BH, Chen EK, Chen YL, Shiea J, et al. Intake of phthalate-tainted foods alters thyroid functions in Taiwanese children. PLoS One 2013;8:e55005.

32. Janesick A, Blumberg B. Endocrine disrupting chemicals and the developmental programming of adipogenesis and obesity. Birth Defects Res C Embryo Today 2011;93:34-50.
33. Ravelli GP, Stein ZA, Susser MW. Obesity in young men after famine exposure in utero and early infancy. $\mathrm{N}$ Engl J Med 1976;295:349-53.

34. Martorell R, Stein AD, Schroeder DG. Early nutrition and later adiposity. J Nutr 2001;131:874S-880S.

35. Ong KK, Loos RJ. Rapid infancy weight gain and subsequent obesity: systematic reviews and hopeful suggestions. Acta Paediatr 2006;95:904-8.

36. Lamb JC 4th, Chapin RE, Teague J, Lawton AD, Reel JR. Reproductive effects of four phthalic acid esters in the mouse. Toxicol Appl Pharmacol 1987;88:255-69.

37. Jarfelt K, Dalgaard M, Hass U, Borch J, Jacobsen H, Ladefoged O. Antiandrogenic effects in male rats perinatally exposed to a mixture of di(2-ethylhexyl) phthalate and di(2-ethylhexyl) adipate. Reprod Toxicol 2005;19:505-15.

38. Meeker JD, Hu H, Cantonwine DE, Lamadrid-Figueroa $\mathrm{H}$, Calafat AM, Ettinger AS, et al. Urinary phthalate metabolites in relation to preterm birth in Mexico city. Environ Health Perspect 2009;117:1587-92.

39. Zhang Y, Lin L, Cao Y, Chen B, Zheng L, Ge RS. Phthalate levels and low birth weight: a nested case-control study of Chinese newborns. J Pediatr 2009;155:500-4.

40. Huang Y, Li J, Garcia JM, Lin H, Wang Y, Yan P, et al. Phthalate levels in cord blood are associated with preterm delivery and fetal growth parameters in Chinese women. PLoS One 2014;9:e87430.

41. Wolff MS, Engel SM, Berkowitz GS, Ye X, Silva MJ, Zhu C, et al. Prenatal phenol and phthalate exposures and birth outcomes. Environ Health Perspect 2008; 116:1092-7.

42. Suzuki Y, Niwa M, Yoshinaga J, Mizumoto Y, Serizawa S, Shiraishi H. Prenatal exposure to phthalate esters and PAHs and birth outcomes. Environ Int 2010;36:699-704.

43. Stahlhut RW, van Wijngaarden E, Dye TD, Cook S, Swan $\mathrm{SH}$. Concentrations of urinary phthalate metabolites are associated with increased waist circumference and insulin resistance in adult U.S. males. Environ Health Perspect 2007;115:876-82.

44. Hatch EE, Nelson JW, Qureshi MM, Weinberg J, Moore LL, Singer M, et al. Association of urinary phthalate metabolite concentrations with body mass index and waist circumference: a cross-sectional study of NHANES data, 1999-2002. Environ Health 2008;7:27.

45. Trasande L, Attina TM, Sathyanarayana S, Spanier AJ, Blustein J. Race/ethnicity-specific associations of urinary phthalates with childhood body mass in a nationally representative sample. Environ Health Perspect 2013;121:501-6.

46. Buser MC, Murray HE, Scinicariello F. Age and sex differences in childhood and adulthood obesity association with phthalates: Analyses of NHANES 2007-2010. Int J Hyg Environ Health 2014 Mar 5 [Epub]. http://dx.doi. org/10.1016/j.ijheh.2014.02.005.

47. Lind PM, Roos V, Ronn M, Johansson L, Ahlstrom H, Kullberg J, et al. Serum concentrations of phthalate metabolites are related to abdominal fat distribution two 
years later in elderly women. Environ Health 2012;11:21.

48. Teitelbaum SL, Mervish N, Moshier EL, Vangeepuram N, Galvez MP, Calafat AM, et al. Associations between phthalate metabolite urinary concentrations and body size measures in New York City children. Environ Res 2012;112:186-93. 